\title{
Forecasting Sales Volumes of Small and Medium-Sized Machine-Building Enterprises
}

\author{
Irina $V$. Ershova ${ }^{1}$, Maria A. Prilutskaya ${ }^{1}$, and Andrey $V$. Klyuev ${ }^{1, *}$ \\ ${ }^{1}$ Department of organization of engineering production, Ural Federal University named after the first \\ President of Russia B.N. Yeltsin, 620002, 19 Mira St, Ekaterinburg, Russia
}

\begin{abstract}
In the article, the authors considered the possibilities of forecasting sales based on the use of $\mathrm{ABC}$ analysis tools, the customer potential coefficient and the degree of customization of orders. The object of the study was five medium-sized machine-building enterprises. The method is based on static grouping and analysis of actual sales volumes in the context of customers and the range of orders. The peculiarity of these enterprises is the presence of a large pool of customers with low repeatability of orders. The analysis showed that the majority of Group A customers have low customer potential and stable or declining demand. The largest increase in orders was observed among the customers of Group B. The level of customization of the order increases customer loyalty, but increasing the level of customization reduces the economic efficiency of the activity. The authors suggest direct planning of the basic part of the sales volume based on the achieved level of orders by customers of Groups $\mathrm{A}$ and $\mathrm{B}$ with the customer potential above 1 . The additional part of the sales volume determined by the goals of the enterprise, its resources and planned based on an increase in the level of customization.
\end{abstract}

\section{Introduction}

The share of small and medium-sized machine-building enterprises in the structure of the Russian economy has been increasing in recent years. Initially, the growth of small and medium-sized enterprises was associated with the restructuring of large enterprises and the outsourcing of non-core divisions (repair and tool divisions), with the development of startups at higher educational institutions. Currently, there is the creation of independent enterprises. For example, according to the List-org website, 103 machine-building enterprises are registered in the Sverdlovsk Region, of which 24 are small enterprises, and 42 are medium-sized enterprises. Of the total number of small enterprises, $34.8 \%$ of affiliated enterprises, $26.2 \%$ of the total number of medium- sized enterprises. 7 enterprises have a negative profit value, the average return on assets is $6.1 \%$, while the median is $4.2 \%$. These enterprises have a large number of customers with low repeatability of orders. To stay on the market, they are forced to move from the classical principles of organizing mass production to customized production.

\footnotetext{
* Corresponding author: a.v.klyuev@gmail.com
} 
The existing methods of forecasting sales volumes are focused on working with a large volume of statistical data or expert assessments. The methods and problems of such approaches are discussed in detail in [1]. The authors note that the effectiveness of many methods depends on the relative benefit that a firm can potentially receive from the costs of collecting and analysing such data. Modified regression models for sales forecasting are considered in $[2,3,4,5,6]$. The use of a machine learning model for sales forecasting is presented in [7, 8]. Integration of various information systems for sales forecasting is described in $[9,10]$. The mentioned models and approaches are typical for mass-demand goods, a large number of customers (for example, for trading companies) and are limited for small and medium-sized enterprises operating in a customized environment.

The effectiveness of customization is usually associated with expensive products [11]. Sales forecasting for the elite segment of the market is considered in [12]. Sales forecasting for small and medium-sized machine-building enterprises in the context of customization is practically not studied.

The study is a continuation of the work [13] and aims to determine the degree of influence of customization on customer retention and subsequent forecasting of sales volumes.

\section{Materials and Methods}

The analysis was carried out for five machine-building enterprises (two small and three medium-sized enterprises). The selected companies are not dependent subsidiaries and there is no influence of the parent company on the volume and range of sales.

The first stage of the study was customers grouping by sales volume (ABC-analysis) and describe the customers of each group. The semantic description of the customers is given in the table 1.

Table 1. Description and characteristics of customer groups for $\mathrm{ABC}$-analysis.

\begin{tabular}{|c|c|c|}
\hline Groups & Description & Characteristics \\
\hline A & $\begin{array}{c}\text { Large enterprises, including } \\
\text { defence industry enterprises }\end{array}$ & $\begin{array}{c}\text { Large volumes of orders, the price with a } \\
\text { minimum margin, short production times, } \\
\text { deferred payment for 90 days or more. }\end{array}$ \\
\hline B & $\begin{array}{c}\text { Medium-sized enterprises } \\
\text { that are comparable in terms } \\
\text { of production volumes to the } \\
\text { analysed enterprises. }\end{array}$ & $\begin{array}{c}\text { Partnership relations. The volume of } \\
\text { products is small, but due to the } \\
\text { uniqueness, you can get additional income. }\end{array}$ \\
\hline C & $\begin{array}{c}\text { Small companies, including } \\
\text { those that do not have their } \\
\text { own production, and are } \\
\text { intermediaries. }\end{array}$ & $\begin{array}{c}\text { One-time customers who can potentially } \\
\text { move to Group B. }\end{array}$ \\
\hline
\end{tabular}

The second stage of the study involved finding the "customer potential" (CP). The growth rate of order volumes was determined during the next 3, 6, 9, 12 months after the client's first contact with the company. The presence of stable growth rates during the year allowed us to identify customers with a large CP. This indicator is measured by the growth rate of sales relative to the first order, provided that the positive dynamics during the year. Studies have shown that the CP value for different clients can be 10 or more.

The task of the third stage of the study was to compare customer groupings by the ABC-analysis method and by customer potential. It was found that only a fraction of Group A clients have relatively high $\mathrm{CP}$ scores. Figures 1,2 and 3 show the corresponding diagrams that were obtained from the data of the three enterprises (they are designated as 
$\mathrm{X}, \mathrm{Y}$ and $\mathrm{Z}$ ). It should be noted that all these enterprises work in completely different branches of machine-building products.

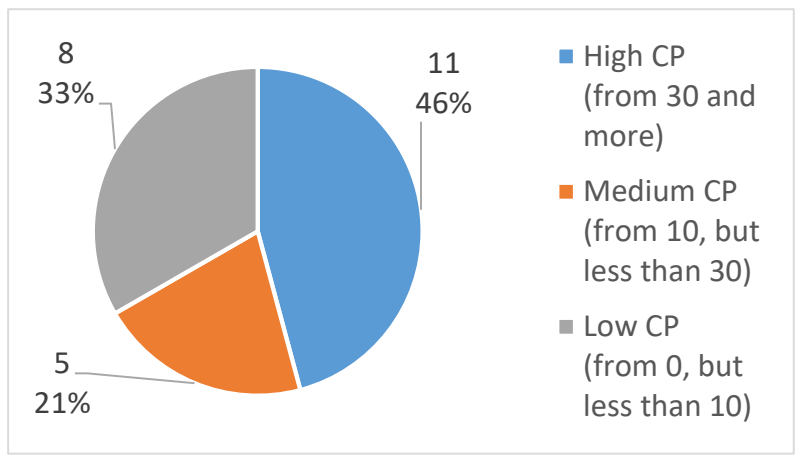

Fig. 1. The structure of Group A customers by the value of the CP indicator in the enterprise $\mathrm{X}$.

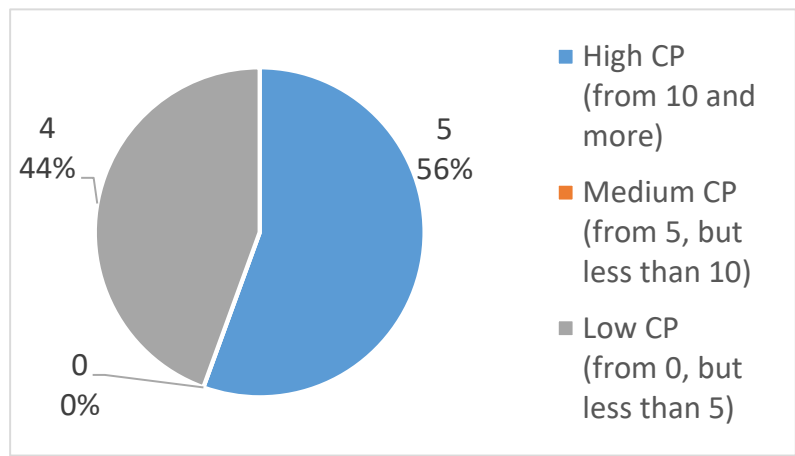

Fig. 2. The structure of Group A customers by the value of the $\mathrm{CP}$ indicator in the enterprise $\mathrm{Y}$.

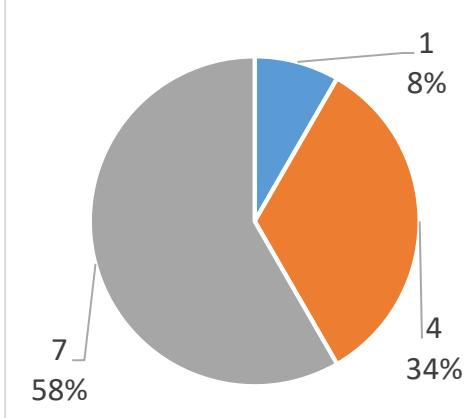

$$
\begin{aligned}
& \text { - High CP } \\
& \text { (from } 3 \text { and } \\
& \text { more) } \\
& \text { - Medium CP } \\
& \text { (from 1, but } \\
& \text { less than 3) } \\
& \text { Low CP } \\
& \text { (from } 0, \text { but } \\
& \text { less than } 1 \text { ) }
\end{aligned}
$$

Fig. 3. The structure of Group A customers by the value of the CP indicator in the enterprise $\mathrm{Z}$.

The CP value is relatively low for a significant part of Group A clients (in Figures 1, 2 and 3 , it is $33 \%, 44 \%$ and $58 \%$, respectively).

The final stage of the study was to determine the dependence of the $\mathrm{CP}$ value and the client's belonging to one of the groups on the level of customization of orders.

To assess the level of customization, the total range of products sold within the study period was divided into separate groups according to the average frequency of actual production within the study period. The products of the enterprises are individual 
components and components. Typical approaches to a customized product, as a product with additional options, are not applicable here. The principle of uniqueness and additional services was adopted as the basis for customizing the order. The list of these groups and their description are given in table 2 .

Table 2. Groups of manufactured products by the average frequency of actual production within the study period.

\begin{tabular}{|c|c|}
\hline Groups & Description \\
\hline F5 & $\begin{array}{c}\text { Once a week and more often, } \\
\text { but less often than once a day. }\end{array}$ \\
\hline F4 & $\begin{array}{c}\text { Once a month and more often, } \\
\text { but less often than once a week. }\end{array}$ \\
\hline F3 & $\begin{array}{c}\text { Once a quarter and more often, } \\
\text { but less often than once a month. }\end{array}$ \\
\hline F2 & $\begin{array}{c}\text { Once a year and more often, } \\
\text { but less often than once a quarter. }\end{array}$ \\
\hline F1 & Less often than once a year. \\
\hline
\end{tabular}

It was accepted that the level of customization is determined by the proportion of those product that fell into the groups F1, F2 and F3. A detailed assessment of the level of customization was carried out according to enterprise $\mathrm{X}$ data. The corresponding sample included 277 customers who placed orders at this enterprise during the period under review.

\section{Results}

The level of customization is not the only explanatory factor for the growth of sales by customer, but its impact on customer retention is significant. $56 \%$ of all customers of the enterprise $\mathrm{X}$ with a CP value of 1 and higher had a level of customization above $60 \%$ (table $3)$.

Table 3. Results of the analysis of the level of customization.

\begin{tabular}{|c|c|c|c|c|c|c|c|}
\hline \multirow{2}{*}{$\begin{array}{c}\text { Level of } \\
\text { customization, } \\
\%\end{array}$} & \multicolumn{3}{|c|}{$\begin{array}{c}\text { Number of clients by ABC- } \\
\text { analysis }\end{array}$} & \multicolumn{4}{|c|}{ Number of clients by CP value } \\
\cline { 2 - 8 } & $\mathrm{A}$ & $\mathrm{B}$ & $\mathrm{C}$ & $\begin{array}{c}\text { from } 30 \\
\text { and more }\end{array}$ & $\begin{array}{c}\text { from } 10 \\
\text { to } 30\end{array}$ & $\begin{array}{c}\text { from } 1 \\
\text { to } 10\end{array}$ & $\begin{array}{c}\text { less than } \\
1\end{array}$ \\
\hline less than $30 \%$ & 6 & 10 & 57 & 3 & 1 & 10 & 59 \\
\hline $\begin{array}{c}\text { from } 30 \% \\
\text { to } 60 \%\end{array}$ & 5 & 13 & 24 & 4 & 4 & 11 & 23 \\
\hline $\begin{array}{c}\text { from } 60 \% \\
\text { and above }\end{array}$ & 13 & 34 & 115 & 7 & 10 & 25 & 120 \\
\hline
\end{tabular}

The great values of the level of customization for customers of Group $\mathrm{C}$ and with a low $\mathrm{CP}$ value is explained by the presence of one-time "trial" orders. 
Additionally, we analyzed the economic consequences of customization. The regression model of the dependence of the annual margin income $(\mathrm{Y})$ on the number of standard orders (X1) and customized orders (X2) showed that the coefficient of influence of customized orders is higher.

$$
Y=0,145 X 1+0,200 X 2
$$

The final conclusion about the level of customization should be made by the company taking into account the required investments in additional equipment and equipment.

Based on our research, we propose the following algorithm for predicting sales volumes for small and medium-sized enterprises.

1. Formation of the base sales volume based on the actual purchases of Group A and B customers with a CP value above 1 .

2. Formation of an additional part of orders for customers of group A and B with CP value less than 1 by increasing the customization coefficient.

\section{References}

1. T. Boone, R. Ganeshan, A. Jain, N.R. Sanders, Forecasting sales in the supply chain: Consumer analytics in the big data era, International Journal of Forecasting, v. 35(1), pp. 170-180 (2019)

2. M.N. Pavlenkov, R.Z. Reimov, Forecasting method for the sales volume of an industrial enterprise, Espacios, v. 40(42), 27 (2019)

3. C.-J. Lu, I.-F. Chen, Identifying important predictors for computer server sales using an effective hybrid forecasting technique, International Journal of Information and Management Sciences, v. 28(3), pp. 213-232 (2017)

4. Z.-P. Fan, Y.-J. Che, Z.-Y. Chen, Product sales forecasting using online reviews and historical sales data: A method combining the Bass model and sentiment analysis, Journal of Business Research, v. 74, pp. 90-100 (2017)

5. R.Y.K. Lau, W. Zhang, W. Xu, Parallel Aspect-Oriented Sentiment Analysis for Sales Forecasting with Big Data, Production and Operations Management, v. 27(10), pp. 1775-1794 (2018)

6. Y.R. Sagaert, E.-H. Aghezzaf, N. Kourentzes, B. Desmet, Temporal big data for tactical sales forecasting in the tire industry, Interfaces, v. 48(2), pp. 121-129 (2018)

7. M. Bohanec, M. Robnik-Šikonja, Borštnar M. Kljajić, Organizational Learning Supported by Machine Learning Models Coupled with General Explanation Methods: A Case of B2B Sales Forecasting, Organizacija, v. 50(3), pp. 217-233 (2017)

8. J. Wei, J. Zhu, C. Huang, Y. Tang, X. Lin, C. Mao, A novel prediction model for sales forecasting based on grey system, Proceedings - 2016 IEEE 9th International Conference on Service-Oriented Computing and Applications SOCA 2016, 7796003 (2016)

9. J.A. Hoyle, R. Dingus, J.H. Wilson, An exploration of sales forecasting: sales manager and salesperson perspectives, Journal of Marketing Analytics, v. 8(3), pp. 127-136 (2020)

10. R. Hirt, N. Kuhl, Y. Peker, G. Satzger, How to Learn from Others: Transfer Machine Learning with Additive Regression Models to Improve Sales Forecasting, Proceedings - 2020 IEEE 22nd Conference on Business Informatics, CBI 2020, v. 1, 9140249 (2020) 
11. E.M. Tishkova, Ya.S. Straukas, Evolution and essence of the customization process, Alley of Science, v. 5(16), pp. 615-620 (2017)

12. A.G. Kuzmin, V.M. Bykov, M.A. Kazaryan, T.P. Danko, V.D. Sekerin, Market of luxury goods and sales forecasting using the network analysis, International Journal of Applied Business and Economic Research, v. 15(21), pp. 439-450 (2017)

13. S.G. Baranchikova, I.V. Ershova, A.V. Klyuev, E.V. Cherepanova, Optimization of the production plan taking according to the customers' strategic importance, IOP Conference Series: Materials Science and Engineering, v. 971(5), 052014 (2020) 